\title{
Changes in Total Polyphenol Content and Antioxidant Capacity of Stinging Nettle (Urtica dioica L.) from Spring to Autumn
}

\author{
Kornélia Kőszegi1*, Erika Békássy-Molnár ${ }^{1}$, Noémi Koczka² ${ }^{2}$ Tímea Kerner¹, \\ Éva Stefanovits-Bányai ${ }^{3}$ \\ 1 Department of Food Engineering, Faculty of Food Science, Szent István University, H-1118 Budapest, Ménesi út 44, Hungary
2 Institute of Horticulture, Faculty of Agricultural and Environmental Sciences, Szent István University,
H-2100 Gödöllö, Páter Károly utca 1, Hungary
${ }^{3}$ Department of Applied Chemistry, Faculty of Food Science, Szent István University, H-1118 Budapest, Villányi út 29-43, Hungary
* Corresponding author, e-mail: Koszegi.Laszlone@etk.szie.hu
}

Received: 08 May 2019, Accepted: 23 August 2019, Published online: 28 October 2019

\begin{abstract}
Total polyphenol content and antioxidant/reducing capacity of stinging nettle (Urtica dioica L.) leaves and roots collected from wildgrown plants were investigated during the vegetation period. From both fresh and dried samples of leaves and roots, water extracts were prepared by brewing at 60,80 and $100{ }^{\circ} \mathrm{C}$ for 3 hours, and ethanolic extracts of $20 \%(\mathrm{v} / \mathrm{v})$ and $70 \%(\mathrm{v} / \mathrm{v})$ by extracting at room temperature for 72 hours. The total polyphenol content was determined spectrophotometrically with Folin-Cioceltau reagent and the antioxidant capacity was measured by ferric reducing ability of plasma (FRAP) assay.

Our results showed that the optimal harvest time is in the spring (April). Water extracts had the highest total polyphenol content and antioxidant capacity in this period. The amount of valuable compounds released increased by higher extraction temperature in both plant parts. In water extracts of nettle leaves, two times higher polyphenol content was obtained than in that of roots. Both kind of ethanolic extractions resulted in a higher polyphenol content in the leaves harvested in the spring period. For the roots, it was higher for samples collected in the autumn, which is also reflected in the values of antioxidant capacity. Water extracts of fresh leaves harvested in April had more than twice higher total polyphenol content than in October. For dried samples, raising the temperature did not cause a significant change in the total polyphenol content, however, it has resulted in increased antioxidant capacity both for the dried leaf and root samples.
\end{abstract}

Keywords

nettle, total polyphenol content, harvest time, heat treatment

\section{Introduction}

Stinging nettle (Urtica dioica L.) is a herbaceous perennial weedy plant. It has spread out worldwide nearly anywhere, it is common in Hungary too. Stinging nettle has been used as a medicinal herb since ancient times, and it is still often applied in traditional and folk medicine for a wide array of disorders. It is widely known as diuretic agent for treatment of rheumatism and arthritis [1]. It has anti-inflammatory, antimicrobial, antioxidative and analgesic effects [2-4]. Nettle is known to boost the immune system and to prevent anaemia [5]. It is suggested to treat hypertension and heart diseases [6], to inhibit the growth of breast [7], prostate [8], and lung [9] tumor cells. It may reduce the symptoms of Alzheimer's disease [10] and respiratory allergies [11]. Aqueous ethanolic extracts of $U$. dioica are demonstrated to be effective for weight reduction in obese or overweight [12]. Medicinal properties of nettle are associated with its high mineral element (Ca, Mg, Zn, Mn, Cu) [13], and vitamin (provitamin A carotenoids, $\left.\mathrm{B}_{2}, \mathrm{~B}_{5}, \mathrm{~B}_{9}, \mathrm{C}, \mathrm{D}, \mathrm{E}, \mathrm{K}\right)$ contents [13-15]. In addition, active compounds with reducing properties such as polyphenols are important for human health. Polyphenol components are secondary metabolites of plants and are involved in defence against biotic and abiotic stresses [16-19]. Consumption of plant polyphenols by vegetables, fruits, and herbs can improve the antioxidant status of human body. 
Due to its very high polyphenol and phenolic acids (rutin, quercetin, isoquercetin, caffeic acid, chlorogenic acid, ferulic acid) content, stinging nettle has a high reducing/antioxidant capacity, besides its antimicrobial activity against human pathogens. Nettle also plays an important role in preventing and healing diseases [13, 20-23].

The aim of this study was to characterize the beneficial effects of nettle leaf and root extracts prepared by different extraction methods and to determine the optimal harvest time of leaves and roots.

\section{Materials and methods}

Leaves and roots of wild grown Urtica dioica were harvested four times during the vegetation period, on brown forest soil in the central region of Hungary. Fresh plant material (in the case of first and last collecting time also dried samples) were analyzed. All investigations were carried out triplicated.

Preparation of fresh samples. Directly after collecting the whole plants, leaves and roots were separated. Fresh leaves were cut into small pieces. Roots were thoroughly washed and finely chopped.

Preparation of dried samples. Leaves and roots of the collected whole plants were separately washed, than dried at $30{ }^{\circ} \mathrm{C}$, in a light-protected, airy place for 2-3 weeks. Dried plant parts were grinded by knife mill (Retsch GM 200 Grindomix) and ball mill (MM 400). The particle size was determined using a Fritsch Analysette 22 laser diffraction apparatus. Particle size of the leaves was $149.96 \pm$ $1.18 \mu \mathrm{m}$, and that of the roots was $42.25 \pm 3.05 \mu \mathrm{m}$.

Determination of dry matter content. The dry matter content of the samples was determined with a KERN MLS 50-3HA160 rapid moisture meter, the results were given in \%. Dry matter content of the fresh leaves was $18.25 \pm$ $0.84 \%$, that of the dried leaves was $90.80 \pm 0.02 \%$. For fresh and dried roots $22.90 \pm 0.90 \%$ and $91.07 \pm 0.08 \%$ were measured, respectively.

Preparation of water extracts. Water extracts were prepared by adding $100 \mathrm{ml}$ of distilled water to $1 \mathrm{~g}$ of fresh samples. Triplicated extracts were placed in a water bath at 60,80 and $100{ }^{\circ} \mathrm{C}$ for 3 hours in a closed system. Control extract was made like a common tea: $1 \mathrm{~g}$ of fresh samples was infused with $100 \mathrm{ml}$ of boiling water $\left(100^{\circ} \mathrm{C}\right)$. Cooled extracts were centrifuged at $13000 \mathrm{rpm}$ for $10 \mathrm{~min}$ at room temperature, and the supernatants were stored at $-32{ }^{\circ} \mathrm{C}$ until analyses.

Preparation of ethanolic extracts. $100 \mathrm{ml}$ of $20 \%$ aqueous ethanol (water/ethanol $80 / 20 \mathrm{v} / \mathrm{v}, 20{ }^{\circ} \mathrm{C}$ ) and of $70 \%$ aqueous ethanol (water/ethanol 30/70 v/v, $20{ }^{\circ} \mathrm{C}$ ) were added to $1 \mathrm{~g}$ of plant samples, than stored at room temperature for $72 \mathrm{~h}$. Extracts were centrifuged at $13000 \mathrm{rpm}$ for $10 \mathrm{~min}$ at room temperature, and the supernatants were stored at $-32{ }^{\circ} \mathrm{C}$ until analyses.

Total polyphenol content (TPC) was determined by the method of Singleton and Rossi [24] with Folin-Ciocalteu reagent. Color change during the reaction was detected by a spectrophotometric method ( $\lambda=760 \mathrm{~nm})$. The results were expressed in gallic acid equivalent (mM GAE/g dry matter).

The total antioxidant capacity of the different extracts was measured by the FRAP method of Benzie and Strain [25]. The reaction causes a blue colour change, which can be detected spectrophotometrically at $\lambda=593 \mathrm{~nm}$. The results were expressed in ascorbic acid equivalent $(\mu \mathrm{M}$ AAE/g dry matter).

\section{Results}

\subsection{Investigation of water extracts during the vegetation period}

Total phenol content and antioxidant capacity of water extracts were determined from the earliest possible harvest time until the end of vegetation.

\subsubsection{Total polyphenol content of fresh samples}

Total polyphenol content measured in the fresh leaves was $30-50 \%$ higher than in the fresh roots, in all water extracts (Fig. 1-2). Results on total phenolic content in water leaf extracts obtained by other authors are in accordance with our data [26-28]. Total polyphenol concentration of water extracts of fresh leaves decreased during the vegetation period, it was the highest in April, and the lowest in October. The sampling time phases did not influence the total polyphenol content of water extracts of the roots, it was constant during the vegetation period.

Based on our results, in the case of water extracts of both fresh leaves and roots, higher temperature resulted in a slight increase of total polyphenol content (Fig. 1-2). This trend could not be found for the leaves harvested in October, at the end of the vegetation period, as the total phenol content decreased with increasing extraction temperature (Fig. 1-2). As shown in the diagrams, polyphenols could be extracted in a higher amount by the longer extraction at higher temperatures compared to the control, common tea preparation method.

In this study, the highest total polyphenol content in water extracts of nettle leaves and roots could be detected 


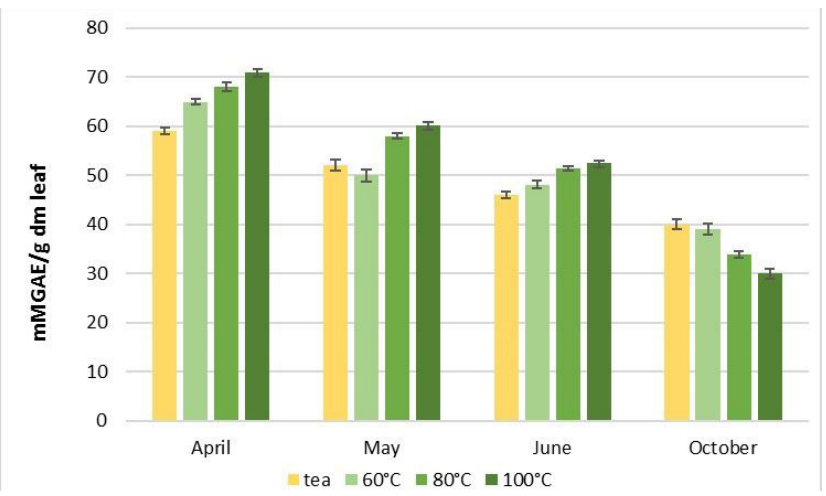

Fig. 1 Changes in total polyphenol content of water extracts of fresh nettle leaves during the vegetation period

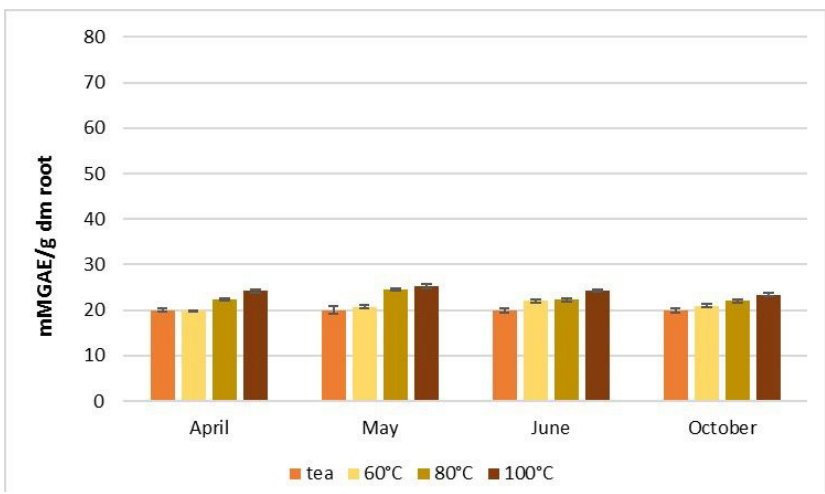

Fig. 2 Changes in total polyphenol content of water extracts of fresh nettle roots during the vegetation period

in April and May, hence the optimal harvest time for both plant parts is in the spring. This result is in accordance with findings published previously [29-30].

\subsubsection{Antioxidant capacity of fresh samples}

Antioxidant capacity of fresh leaves was approximately two-fold larger at the beginning of vegetation than that of roots. This difference was smaller at the other sampling times (Fig. 3-4).

Antioxidant capacity of water leaf extracts was influenced by the sampling time. It was the highest for the fresh leaves collected in April. In May and June this parameter had similar values, but significantly lower than at the beginning of the vegetation. The lowest antioxidant capacity was obtained for leaves harvested in autumn. However, the phenological phase had no effect on antioxidant capacity of root extracts (Fig. 3-4).

The extraction temperature and brewing time influenced the antioxidant capacity of fresh leaves only at the first and the last harvest time, it was greater at longer extraction and higher temperature. However, in May and June, the antioxidant capacity was significantly lower in water extracts

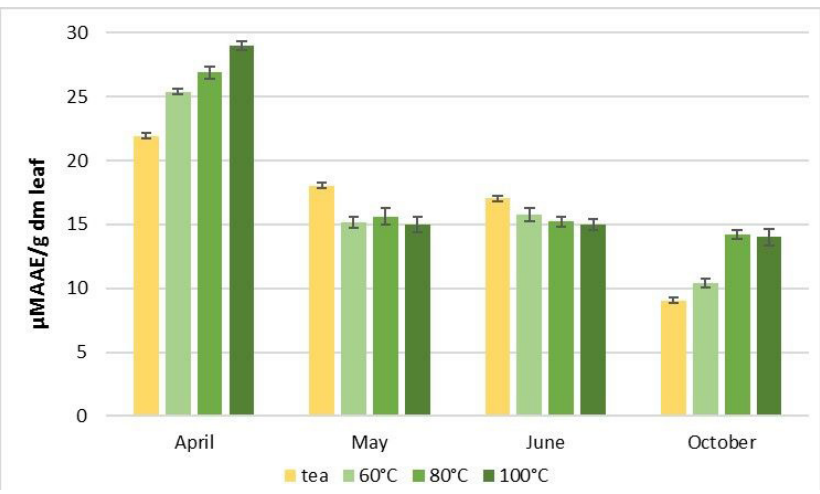

Fig. 3 Changes in antioxidant capacity of water extracts of fresh nettle leaves during the vegetation period

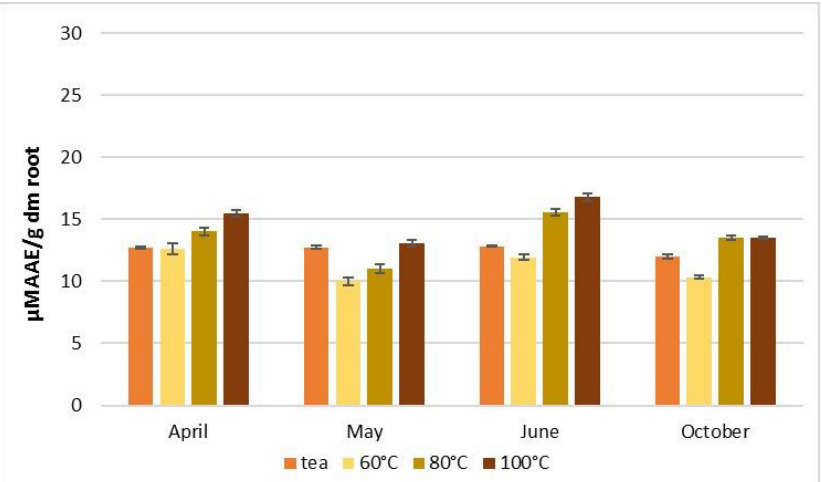

Fig. 4 Changes in antioxidant capacity of water extracts of fresh nettle roots during the vegetation period

brewed for 3 hours than in the infusion (control). The antioxidant capacity in water extracts of fresh roots was significantly higher by extraction at 80 and $100{ }^{\circ} \mathrm{C}$ for 3 hours than at $60^{\circ} \mathrm{C}$ and in the control infusion.

\subsection{Investigation of ethanolic extracts during the vegetation period}

\subsubsection{Total polyphenol content of fresh samples}

In the spring and summer, the total polyphenol content of fresh nettle leaves measured in ethanolic extracts was significantly higher than that of fresh roots (Fig. 5). This result is in accordance with the findings of Otles and Yalcin [20] who investigated methanolic extracts of nettle leaves and roots.

For the lower ethanolic concentration of leaves, the highest total phenolic content was detected in April (Fig. 5). Total phenolic level was significantly lower in May, at the phenological stage of stalk elongation, and it was high at the flowering stage. The higher ethanolic concentration resulted in constant high total phenolic concentrations for the leaves collected in the spring and summer, and a significantly lower phenolic level was measured in the 
autumn. The phenolic concentration of leaves decreased, while that of roots increased slightly in October.

Changes in the total polyphenol content of nettle leaves during the vegetation period were detected also by other authors, however, with diverse results. Nencu et al. [29] measured the highest phenolic content in the young leaves in the spring, and its level decreased up to the flowering stage of the plant. Biesiada et al.[31] found that total polyphenol content of leaves decreases continuously from spring to autumn. However, Roslon and Weglarz [30] reported an increase in the total phenol content of nettle leaves up to the flowering, and then a decline in the phenolic concentration.

Total polyphenol content in water extracts of fresh leaves and roots was significantly greater than in ethanolic extracts at every harvest time. In the case of roots, similar values were found in both water and ethanolic extracts.

The higher concentration of ethanolic solvent caused a decrease in the polyphenol level of leaf extracts, especially in samples collected in April and June, while in May and in October significant differences were not found between the $20 \%$ and $70 \%$ solvent (Fig. 5).

\subsubsection{Antioxidant capacity of fresh samples}

The higher concentration of ethanolic solvent resulted in significantly higher antioxidant capacity for both fresh leaves and roots at every harvest time (Fig. 6).

In leaf extracts of the lower ethanolic concentration, FRAP values showed the same trend during the vegetation as total phenol content. The highest antioxidant capacity was obtained in April, then it decreased at the phenological stage of growth, it increased again at the flowering, while the FRAP value was the lowest in the autumn (Fig. 6). The higher etanolic concentration caused higher antioxidant activities in the leaf extracts, FRAP values were the highest in April and May, then the antioxidant capacity decreased in the summer, and showed the minimum level in October. The same trend was obtained by some authors [31, 32].

\subsection{Investigation of dried leaves and roots}

Table 1 summarizes the data measured for both dried leaves and roots collected at the beginning and at the end of vegetation. Our data for total polyphenolic level in extracts of dried nettle leaves are in accordance with results reported by other authors $[33,34]$.

Total polyphenol content of dried leaves was significantly higher for samples collected in April than for that

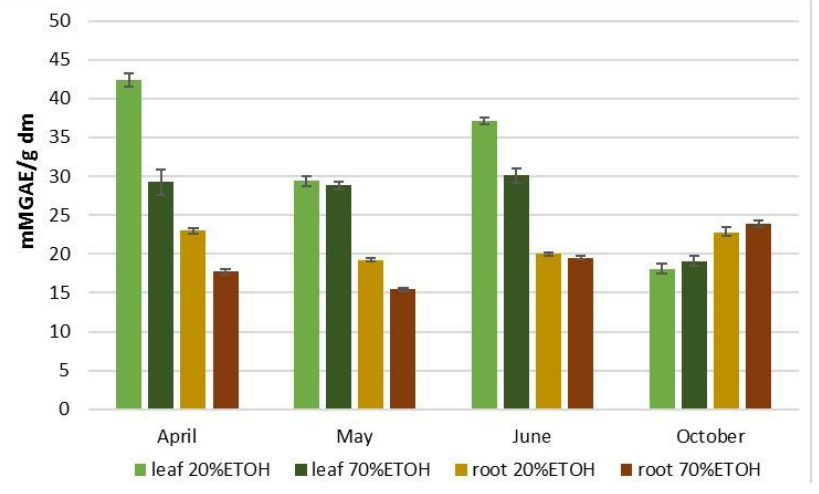

Fig. 5 Changes in total phenol content of ethanolic extracts of fresh nettle leaves and roots during the vegetation period

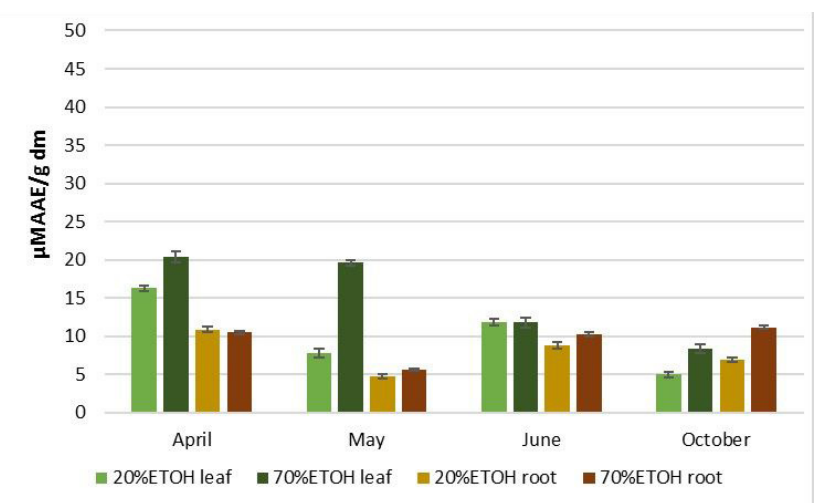

Fig. 6 Changes in antioxidant capacity of ethanolic extracts of fresh nettle leaves and roots during the vegetation period

in October. This relationship could be obtained for all extraction methods. Dried roots collected in April also showed greater total polyphenol content regardless of heat treatment and ethanol concentration.

Total polyphenol content was found to be higher for the leaves than for the roots with all extraction methods.

The extraction method had a considerable effect on the polyphenol level: water extracts had higher total phenol content than ethanolic extracts. The brewing temperature and time had much lower influence than in the case of fresh samples.

Antioxidant capacity also showed higher values for both dried leaves and roots harvested in April than for that in October. However, the difference between the two collecting times was not as high as for the total phenol content.

Antioxidant capacity of both leaf and root extracts increased with higher extraction temperature, the most effective extraction method was the brewing at $100{ }^{\circ} \mathrm{C}$ for 3 hours. The higher ethanol concentration caused a decrease in antioxidant capacity for both leaves and roots. 
Table 1 Total phenol content and antioxidant capacity of dried nettle leaves and roots

\begin{tabular}{|c|c|c|c|c|c|}
\hline & & April & October & April & October \\
\hline & & \multicolumn{2}{|c|}{ mMGAE/g } & \multicolumn{2}{|c|}{$\mu \mathrm{MAAE} / \mathrm{g}$} \\
\hline \multirow[t]{2}{*}{ tea } & leaf & $101.42 \pm 3.34$ & $50.42 \pm 1.34$ & $10.28 \pm 0.78$ & $11.02 \pm 0.07$ \\
\hline & root & $28.42 \pm 0.60$ & $25.42 \pm 0.60$ & $9.01 \pm 0.28$ & $8.52 \pm 0.07$ \\
\hline \multirow[t]{2}{*}{$60^{\circ} \mathrm{C}$ water } & leaf & $97.23 \pm 1.70$ & $29.20 \pm 0.94$ & $10.86 \pm 0.18$ & $11.87 \pm 0.06$ \\
\hline & root & $20.87 \pm 0.52$ & $12.23 \pm 0.47$ & $10.43 \pm 0.45$ & $6.79 \pm 0.03$ \\
\hline \multirow[t]{2}{*}{$80^{\circ} \mathrm{C}$ water } & leaf & $99.06 \pm 1.65$ & $36.30 \pm 0.41$ & $21.89 \pm 0.77$ & $19.71 \pm 0.07$ \\
\hline & root & $23.80 \pm 1.20$ & $13.48 \pm 0.34$ & $13.71 \pm 0.71$ & $8.55 \pm 0.06$ \\
\hline \multirow[t]{2}{*}{$100^{\circ} \mathrm{C}$ water } & leaf & $106.64 \pm 4.21$ & $38.37 \pm 0.53$ & $28.57 \pm 0.52$ & $25.32 \pm 0.13$ \\
\hline & root & $28.79 \pm 1.06$ & $18.78 \pm 0.35$ & $15.32 \pm 0.57$ & $10.89 \pm 0.03$ \\
\hline \multirow[t]{2}{*}{$20 \% \mathrm{EtOH}$} & leaf & $66.21 \pm 5.43$ & $18.46 \pm 0.50$ & $12.29 \pm 0.57$ & $7.27 \pm 0.07$ \\
\hline & root & $25.00 \pm 0.42$ & $10.21 \pm 0.58$ & $12.27 \pm 0.57$ & $4.90 \pm 0.09$ \\
\hline \multirow[t]{2}{*}{$70 \% \mathrm{EtOH}$} & leaf & $34.82 \pm 1.86$ & $11.28 \pm 0.55$ & $10.38 \pm 1.59$ & $10.67 \pm 0.11$ \\
\hline & root & $24.14 \pm 0.41$ & $15.59 \pm 0.37$ & $11.68 \pm 0.85$ & $5.80 \pm 0.09$ \\
\hline
\end{tabular}

\section{Conclusions}

In this study, the influence of the phenological stages on total polyphenol content and antioxidant activity of leaves and roots of stinging nettle (Urtica dioica L.) were extensively investigated. Both fresh and dried plant parts were extracted in different ways. Water extraction was made at different temperatures, and ethanolic extraction was carried out with two different concentrations.

Leaves of stinging nettle accumulate the polyphenol compounds in a higher amount than the roots during the whole vegetation period. This could be stated regardless of the extraction solvent.

The highest polyphenol content and health-promoting reducing activity were found in the water extracts of fresh leaves collected at the beginning of the vegetation period.

Raising the brewing temperature resulted in a significant increase of total polyphenol content and antioxidant capacity. It may be caused by further synthesis of polyphenol compounds in secondary processes improving the reducing activity.

The total polyphenol content of the leaves decreased from spring to autumn. However, that of roots showed a slight increase at the end of the vegetation.

Water extraction allows a release of more polyphenol compounds having reducing activity, compared to the ethanolic extraction. Using longer extraction time than for common tea preparation (infusion) is definitely a more effective method.

Most of the scientific works investigating polyphenols and antioxidant activity in stinging nettle, are focused on alcoholic leaf extracts. The total polyphenol levels detected in this study were similar to the findings of some authors [27, 29, 31, 35, 36], but differed markedly from the results of other researchers [28, 37-39]. These high differences might be caused by several biotic and abiotic factors. Some researchers [20, 39] reported that the habitat has a big influence on the accumulation of phenolic compounds in nettle leaves. As shown also in this study, total phenol content and antioxidant activity vary greatly among the different phenological stages of the plant [2931]. The extraction solvent and the extraction conditions have a determining effect on the antioxidant properties of the extracts [35].

For acquiring the highest polyphenol level and antioxidant properties, it is recommended to harvest nettle leaves in the spring, at the beginning of the vegetation period. By extraction of dried leaves, more reducing compounds could be detected than in the case of fresh plant material, probably due to the smaller and more homogeneous particle size of dried samples.

\section{Acknowledgement}

"The Project is was supported by the European Structural and Investment Funds (grant agreement no. VEKOP-2.3.315-2017-00022), "by the Higher Education Institutional Excellence Program (20430-3/2018/FEKUTSTRAT) awarded by the Ministry of Human Capacities within the framework of plant breeding and plant protection researches of Szent István University, and by the European Union and co-financed by the European Social Fund (grant agreement no. EFOP-3.6.3-VEKOP-16-2017-00005)." 


\section{References}

[1] Rajput, P., Chaudhary, M., Sharma, R. A. "Phytochemical and pharmacological importance of Genus Urtica - A review", International Journal of Pharmaceutical Sciences and Research, 6, pp. 1387-1396, 2018.

https://doi.org/10.13040/IJPSR.0975-8232.9(4).1387-96

[2] Farag, M. A., Weigend, M., Luebert, F., Brokamp, G., Wessjohann, L. A. "Phytochemical, phylogenetic, and anti-inflammatory evaluation of 43 Urtica accessions (stinging nettle) based on UPLC-QTOF-MS metabolomic profiles", Phytochemistry, 96, pp. 170-183, 2013.

https://doi.org/10.1016/j.phytochem.2013.09.016

[3] Gülçin, İ., Küfrevioğlu, Ö. İ., Oktay, M., Büyükokuroğlu, M. E. "Antioxidant, antimicrobial, antiulcer and analgesic activities of nettle (Urtica dioica L.)", Journal of Ethnopharmacology, 90(2-3), pp. 205-215, 2004.

https://doi.org/10.1016/j.jep.2003.09.028

[4] Yener, Z., Celik, I., Ilhan, F., Bal, R. "Effects of Urtica dioica L. seed on lipid peroxidation, antioxidants and liver pathology in aflatoxin-induced tissue injury in rats", Food and Chemical Toxicology, 47(2), pp. 418-424, 2009.

https://doi.org/10.1016/j.fet.2008.11.031

[5] Siyukhov, H. R., Skhalyakhov, A. A., Tazova, Z. T., Lunina, L. V., Chich, S. K. "Scientific justification and development of critical solution for the production of phytocomposite mixtures to enrich nonalcoholic beverages", Journal of Pharmaceutical Sciences and Research, 10(6), pp. 1511-1516, 2018.

[6] Vajic, U. J., Grujic-Milanovic, J., Miloradovic, Z., Jovovic, D., Ivanov, M., Karanovic, D., Savikin, K., Bugarski, B., MihailovicStanojevic, N. "Urtica dioica L. leaf extract modulates blood pressure and oxidative stress in spontaneously hypertensive rats", Phytomedicine, 46, pp. 39-45, 2018.

https://doi.org/10.1016/j.phymed.2018.04.037

[7] Mansoori, B., Mohamaddi, A., Hashemzadeh, S., Shirjang, S., Baradaran, A., Asadi, M., Doustvandi, M. A., Baradaran, B. "Urtica dioica extract suppresses miR-21 and metastasis-related genes in breast cancer", Biomedicine and Pharmacotherapy, 93, pp. 95-102, 2017.

https://doi.org/10.1016/j.biopha.2017.06.021

[8] Levy, A., Sivanesan, D., Murugan, R., Jornadal, J., Quinonez, Y., Jaffe, M., Rathinavelu, A. "Urtica dioica Induces Cytotoxicity in Human Prostate Carcinoma LNCaP Cells: Involvement of Oxidative Stress, Mitochondrial Depolarization and Apoptosis", Tropical Journal of Pharmaceutical Research, 13(5), pp. 711-717, 2014.

https://doi.org/10.4314/tjpr.v13i5.9

[9] D’Abrosca, B., Ciaramella, V., Graziani, V., Papaccio, F., Della Corte, C. M., Potenza, N., Fiorentino, A., Ciardiello, F., Morgillo, F. "Urtica dioica L. inhibits proliferation and enhances cisplatin cytotoxicity in NSCLC cells via Endoplasmic Reticulumstress mediated apoptosis", Scientific Reports, 9, Article number: 4986, 2019.

https://doi.org/10.1038/s41598-019-41372-1
[10] Anand, A., Patience, A. A., Sharma, N., Khurana, N. "The present and future of pharmacotherapy of Alzheimer's disease: A comprehensive review", European Journal of Pharmacology, 815, pp. 364375, 2017.

https://doi.org/10.1016/j.ejphar.2017.09.043

[11] Cuicina, L. G., Macêdo, R. O. "Thermoanalytical characterization of plant drug and extract of Urtica dioica L. and kinetic parameters analysis", Journal of Thermal Analysis and Calorimetry, 133(1), pp. 591-602, 2018.

https://doi.org/10.1007/s10973-018-6986-4

[12] Askari Ashtiani A. R., Vahidian-Rezazadeh, M., Jafari, M., Galdavi, R., Mohammadi, M. "Study of Changes in The Plasma Levels of Chemerin of Women with Overweight and Obese During a Period of Endurance Training On a Cycle-Ergometer Using Hydroalcoholic Extract of Urtica", Pharmacophore, 9(2), pp. 72-79, 2018.

[13] Said, A. A. H., Otmani I. S. E., Derfoufi, S., Benmoussa, A. "Highlights on nutritional and therapeutic value of stinging nettle (Urtica Dioica)", International Journal of Pharmacy and Pharmaceutical Sciences, 7(10), pp. 8-14, 2015.

[14] Đurović, S., Šorgić, S., Radojković, M., Zeković, Z. "Elemental profile of stinging nettle leaves obtained by ICP-OES analysis", In: 4th Conference of Young Chemists of Serbia, Belgrade, Serbia, 2016.

https://doi.org/10.13140/RG.2.2.33367.27041

[15] Wolska, J., Czop, M., Jakubczyk, K., Janda, K. "Influence of temperature and brewing time of nettle (Urtica dioica L.) infusions on vitamin C content", Roczniki Panstwowego Zakladu Higieny, 67(4), pp. 367-371, 2016.

[16] Pandey, K. B., Rizvi, S. I. "Plant Polyphenols as Dietary Antioxidants in Human Health and Disease", Oxidative Medicine and Cellular Longevity, 2(5), pp. 270-278, 2009. https://doi.org/10.4161/oxim.2.5.9498

[17] Kulbat, K. "The role of phenolic compounds in plant resistance", Biotechnology and Food Science, 80(2), pp. 97-108, 2016.

[18] Ibrahim, M., Rehman, K., Razzaq, A., Hussain, I., Farooq, T., Hussain, A., Akash, M. S. H. "Investigations of Phytochemical Constituents and Their Pharmacological Properties Isolated from the Genus Urtica: Critical Review and Analysis", Critical Reviews in Eukaryotic Gene Expression, 28(1), pp. 25-66, 2018. https://doi.org/10.1615/CritRevEukaryotGeneExpr.2018020389

[19] Carvalho, A. R., Costa, G., Figueirinha, A., Liberal, J., Prior, J. A. V., Lopes, M. C., Cruz, M. T., Batista, M. T. "Urtica spp.: Phenolic composition, safety, antioxidant and anti-inflammatory activities", Food Research International, 99(1), pp. 485-494, 2017. https://doi.org/10.1016/j.foodres.2017.06.008

[20] Otles, S., Yalcin, B. "Phenolic Compounds Analysis of Root, Stalk, and Leaves of Nettle", The Scientific World Journal, 2012, Article ID 564367, 2012.

https://doi.org/10.1100/2012/564367 
[21] Orčić, D., Francišković, M., Bekvalac, K., Svirčev, E., Beara, I., Lesjak, M., Mimica-Dukić, N. "Quantitative determination of plant phenolics in Urtica dioica extracts by high-performance liquid chromatography coupled with tandem mass spectrometric detection", Food Chemistry, 143, pp. 48-53, 2014. https://doi.org/10.1016/j.foodchem.2013.07.097

[22] Nazar, A. K. M. "Evaluation of antibacterial activities of Urtica dioica against some pathogenic bacterial strains", International Journal of Current Advanced Research, 4(7), pp. 216-220, 2015.

[23] Ghaima, K. K., Hashim, N. M., Ali, S. A. "Antibacterial and antioxidant activities of ethyl acetate extract of nettle (Urtica dioica) and dandelion (Taraxacum officinale)", Journal of Applied Pharmaceutical Science, 5, pp. 96-99, 2013. https://doi.org/10.7324/JAPS.2013.3518

[24] Singleton, V. L., Rossi, J. A. "Colorymetry of Total Phenolics with Phosphomolybdic-Phosphotunstic Acid Reagents", American Journal of Enology and Viticulture, 16, pp. 144-158, 1965.

[25] Benzie, I. F. F., Strain, J. J. "The Ferric Reducing Ability of Plasma (FRAP) as a Measure of "Antioxidant Power": The FRAP Assay", Analytical Biochemistry, 239(1), pp. 70-76, 1996. https://doi.org/10.1006/abio.1996.0292

[26] Shonte, T. T. "Sensory and nutritional properties of stinging nettle (Urtica dioica $\mathrm{L}$.) leaves and leaf infusions", $\mathrm{PhD}$ dissertation, University of Pretoria, 2017.

[27] Mavi, A., Terzi, Z., Özgen, U., Yildirim, A., Coşkun, M. "Antioxidant properties of some medicinal plants: Prangos ferulacea (Apiaceae), Sedum sempervivoides (Crassulaceae), Malva neglecta (Malvaceae), Cruciata taurica (Rubiaceae), Rosa pimpinellifolia (Rosaceae), Galium verum subsp. verum (Rubiaceae), Urtica dioica (Urticaceae)", Biological and Pharmaceutical Bulletin, 27(5), pp. 702-705, 2004 https://doi.org/10.1248/bpb.27.702

[28] Hosseini, M., Qujeq, D., Tamaddoni, A., Ranaee, M., HajianTilaki, K. "Effects of Anethum graveolens, Urtica dioica, Milk thistle Aqueous Extract and Deferoxamine on total iron binding capacity, iron and ferritin levels", International Journal of Research in Applied and Basic Medical Sciences, 5(1), pp. 36-43, 2019.

[29] Nencu, I., Vlase, L., Istudor, V., Duţu, L.E., Gîrd, C.E., "Preliminary research regarding the therapeutic uses of Urtica dioica L. note II. The dynamics of accumulation of total phenolic compounds and ascorbic acid", Farmacia, 60(4), pp. 493-500, 2012.

[30] Roslon W., Weglarz Z. "Polyphenolic acids of female and male forms of Urtica dioica", In: ISHS Acta Horticulturae, 597: International Conference on Medicinal and Aromatic Plants (part II), Budapest, Hungary, 2003, pp. 101-104. https://doi.org/10.17660/ActaHortic.2003.597.12
[31] Biesiada, A., Kucharska, A., Sokół-Łętowska, A., Kuś, A. "Effect of the age of plantation and harvest term on chemical composition and antioxidant avctivity of stinging nettle (Urtica dioica L.)", Ecological Chemistry and Engineering A, 17(9), pp. 1061-1067, 2010.

[32] Zeipiņa, S., Alsiņa, I., Lepse, L., Dūma, M. "Antioxidant activity in nettle (Urtica dioica L.) and garden orache (Atriplex hortensis L.) leaves during vegetation period", Cheminè Technologija, 66(1), pp. 29-33, 2015. https://doi.org/10.5755/j01.ct.66.1.12055

[33] Adhikari, B.M., Bajracharya, A., Shrestha, A. K. "Comparison of nutritional properties of stinging nettle (Urtica dioica) flour with wheat and barley flours", Food Science and Nutrition, 4(1), pp. 119-124, 2016. https://doi.org/10.1002/fsn3.259

[34] Almajano, M. P., Carbó, R., Jiménez, J. A. L., Gordon, M. H. "Antioxidant and antimicrobial activities of tea infusions", Food Chemistry, 108(1), pp. 55-63, 2008. https://doi.org/10.1016/j.foodchem.2007.10.040

[35] Joshi, B. C., Mukhija, M., Semwal, S. "Antioxidant potential and total phenolic content of Urtica dioica (whole plant)", Journal of Applied Pharmacy, 7, pp. 98-105, 2015. https://doi.org/10.21065/19204159.7.2.98

[36] Hudec, J., Burdová, M., Kobida, L., Komora, L., Macho, V., Kogan, G., Turianica, I., Kochanová, R., Ložek, O., Habán, M., Chlebo, P. "Antioxidant Capacity Changes and Phenolic Profile of Echinacea purpurea, Nettle (Urtica dioica L.), and Dandelion (Taraxacum officinale) after Application of Polyamine and Phenolic Biosynthesis Regulators", Journal of Agricultural and Food Chemistry, 55(14), pp. 5689-5696, 2007. https://doi.org/10.1021/jf070777c

[37] Fattahi, S., Zabihi, E., Abedian, Z., Pourbagher, R., Motevalizadeh Ardekani, A., Mostafazadeh, A., Akhavan-Niaki, H. "Total phenolic and flavonoid contents of aqueous extract of stinging nettle and in vitro antiproliferative effect on Hela and BT-474 cell lines", International Journal of Molecular and Cellular Medicine, 3(2), pp. 102-107, 2014.

[38] Kukrić, Z. Z., Topalić-Trivunović, L. N., Kukavica, B. M., Matoš, S. B., Pavičić, S. S., Boroja, M. M., Savić, A. V. "Characterization of antioxidant and antimicrobial activities of nettle leaves (Urtica dioica L.)", Acta Periodica Technica, 43, pp. 257-272, 2012. https://doi.org/10.2298/APT1243257K

[39] Koczka, N., Petersz, D., Stefanovits-Banyai, E. "Total phenol content and antioxidant capacity (FRAP) of Urtica dioica L. leaf extracts", In: ISHS Acta Horticulturae, 1099: II International Symposium on Horticulture in Europe, Anger, France, 2015, pp. 207-210. https://doi.org/10.17660/ActaHortic.2015.1099.21 